\title{
Metallurgy at the Crossroads: New analyses of copper-based objects at Tianshanbeilu, eastern Xinjiang, China
}

\author{
LIU Cheng ${ }^{1}$, LIU Ruiliang ${ }^{2 *}$, ZHOU Pengcheng ${ }^{3}$, LU, Chun ${ }^{4}$, YANG Cengxin ${ }^{5}$, A. Mark POLLARD ${ }^{2}$, Peter \\ HOMMEL $^{6}$, MA Jian ${ }^{1}$, CUI Jianfeng ${ }^{7}$, Peter. BRAY ${ }^{8,9}$, TONG Jianyi ${ }^{1}$ and Jessica RAWSON ${ }^{2}$ \\ 1 School of Cultural Heritage, Northwest University, Xi'an, 710069, China \\ 2 School of Archaeology, University of Oxford, Oxford, UK (OX1 3TG) \\ 3 Xi'an Museum, Xi'an, 710068, China \\ 4 Shandong University of Finance and Economics Library, Jinan, 250012, China \\ 5 School of Electronic Engineering, Xidian University, Xi'an, 710068, China \\ 6 Department of Archaeology, Classics and Egyptology, University of Liverpool, Liverpool, UK (L7 7BD) \\ 7 School of Archaeology and Museology, Peking University, Beijing, 100871, China \\ 8 British Museum, London, UK (WC1B 3DG) \\ 9 Department of Archaeology, University of Reading, Reading, UK (RG6 6AB)
}

\begin{abstract}
Tianshanbeilu is the largest Bronze Age site in eastern Xinjiang, China. Stretching across the entire second millennium BC, it performed a prominent role in connecting the Hexi corridor, Central China and the steppe. A further insight into the metallurgical tradition and the metal supply network is of vital importance to improve our understanding of its multi-connected nature. This paper offers a new set of chemical and isotopic data on the copper-based objects at Tianshanbeilu, including alloying elements, trace elements (impurities) and lead isotopes. Combining the concentrations of arsenic and antimony reveals that arsenic was introduced to copper partially due to the use of specific minerals tethrahedritetennantite. Lead isotopes demonstrate that multiple sources of copper were employed at Tianshanbeilu and a majority of them are characterized by common lead, which appears rather different from those of the Central Plains and the Hexi corridor, but highly consistent with local ores. Surprisingly, one object at Tianshanbeilu contains the well-known highly radiogenic lead. This object undoubtedly marks the westernmost boundary of the distribution of the highly radiogenic lead. We also anticipate that more lead isotopic analyses in NW China will further contribute to the study of the highly radiogenic lead in Central China.
\end{abstract}

Key words: Tianshanbeilu, Metallurgy; Chemical and isotopic analysis; Highly radiogenic lead.

Email: ruiliang.liu@arch.ox.ac.uk

\section{Introduction}

Over the last fifty years, the excavations and investigations focussed on the eastern part of Xinjiang province in China have significantly advanced our understanding of the complex processes of interaction and exchange among the prehistoric communities of eastern Eurasia (Millard, 2007; Han, 2007). The rapidly increasing database of copper-based objects discovered in this area has not only aroused research interest in the technological traditions of prehistoric Xinjiang, but also provided critically important data to compare and contrast with analytical work conducted in Central China and the Eurasian steppe (Mei, 2000; Qian, 2006; Linduff, 2004). Such comparative studies are leading us towards a more complete picture of the processes by which metallurgical innovations were adopted and transformed within different local contexts, as well as their wider impact on contemporary society (Li, 2005; Mei, 2003; Kuzmina, 2007; Chernykh, 1992, 2017; Sherratt, 2006).

This paper presents a new set of chemical and isotopic measurements of the copper-based objects from the site of Tianshanbeilu in eastern Xinjiang, dating to the second millennium BC (Fig. 1). It fills an important gap in discussions of the introduction and uptake of metallurgy in eastern Eurasia and provides the first opportunity for scholars to combine data on lead isotopes, alloying elements and trace elements from the same objects in the study of archaeometallurgy in eastern Xinjiang. The over-arching question in the current study is to explore the sources and the types of metal (particularly copper and lead) and the alloying technology employed at Tianshanbeilu. By combining new analytical results with existing data from the published literature (Mei, 2000; Qian, 2006; Han and Sun, 2004), it is clear that multiple alloy compositions were employed at Tianshanbeilu. The variation in both lead isotopic data and trace element impurity patterns suggest that the copper used in the production of the artefacts recovered from Tianshanbeilu was derived from multiple sources. This diversity, in 
both the alloying practices and sources of raw materials, helps to reinforce the interconnected nature of the site, already suggested in previous scholarship based primarily on typological analysis. A particularly significant result of the new analytical programme is the identification of a copper sample containing highly radiogenic lead (HRL) at Tianshanbeilu. This find at Tianshanbeilu marks the westernmost edge of the distribution of HRL in China, and significantly contributes to the puzzle of the use of HRL in China.

The Tianshanbeilu site is located in the modern Hami city, eastern Xinjiang (E 92 $\left.50^{\prime} 31^{\prime \prime}, \mathrm{N} 42^{\circ} 53^{\prime 2} 23^{\prime \prime}\right)$. It occupies a geographically important location as the next stop after Hami on the eastward journey along the wellknown Hexi corridor. Tianshanbeilu was initially called the Linya Cemetery or Yanmansu Kuanglinchang Banshichu Cemetery. A series of excavations were carried out between 1988 and 1997 by local institutions, revealing 706 tombs and recovering more than 3000 artefacts, including pottery, copper-based objects, gold, silver, bones, stones, cowries, turquoise and glass (Gong, 1997; Shui, 1993; Chen, 1990). All of these materials are being recorded and characterized by Northwest University of China since 2016. Its chronological span is usually assigned to the second millennium BC. The importance of this site for our understanding of the archaeology of Eurasia is captured by Mei J (2003: 21) who describes it as 'pivotal... in bridging the early bronze cultures to the east and west.'.

The material culture at Tianshanbeilu consists of two major bodies of artefacts, pottery and copper-based objects. The repertoire of pottery, particularly the painted wares, provides a clear typological connection to those of the contemporary Siba and Qijia cultures in the Hexi Corridor, strongly implying an eastern connection (Mei, 2000; Mei et al., 2015; Li, 2005; Han, 2007). An initial study of the metalwork from the site also supported this connection. The personal adornments and small implements which dominate the assemblage-earrings, bracelets, mirrors, beads, plaques, buckles, knives, awls, axes and tubes-show close similarities in typology to those recovered from Siba and Qijia sites (Qian, 2006; Mei, 2000). Similar alloying practices are also widely shared across between these regions. Careful archaeometallurgical examination has attested the simultaneous employment of pure copper, tin-bronze, leaded bronze, arsenic copper and arsenic bronze, together with the techniques of casting, forging, annealing and cold-working in both eastern Xinjiang and the Hexi Corridor (Mei, 2000; Li and Shui, 2000; Li, 2002; Li, 2009; Jaang, 2015;). However, the metalwork at Tianshanbeilu also shows connections stretching out to the north and west into the Eurasian steppe. Typologically speaking, the closest ties with neighbouring areas of the steppe are seen in the Late Bronze Age, associated with the late Andronovo and Corded Ware horizons in Eastern Kazakhstan and southern Siberia (Kuzmina, 2007: 265). In their initial review of this material evidence for contact between western Xinjiang and the steppe, Mei and Shell (1999) concluded that the eastern boundary of 'Andronovo cultural influence' may have reached as far as the Hami region. The finds from Tianshanbeilu may suggest a somewhat broader chronological pattern of contact. It has been suggested that general material categories seen at Tianshanbeilu find parallels with both the earlier Middle Bronze Age communities of the Sayan-Altai and the characteristic material of the Karasuk culture (Zhang, 2017). Except for the pottery and metals, other sorts of remains, though in much smaller quantities, illustrate some cultural communication with the similar nature. One carnelian bead discovered at Tianshanbeilu may indicate a connection to Central or even Western Asia (Rawson, 2010). Still wider networks, attested in the presence of numerous cowry shells - whose ultimate origins lie either in the Indian or Pacific Ocean-underline complexity and extent of contemporary chains of exchange and communication (Bin, 2001; also see Vadetskaya et al. (2014) for a note of caution).

In addition to the material culture, archaeobotanical and isotopic analysis also places Tianshanbeilu, and Xinjiang more generally, as a point of contact between east and west (Dong et al., 2017; Wang et al., 2017; Liu et al. accepted). The introduction of millet as a major dietary staple has been identified in Late Bronze and Early Iron Age communities in many parts of the Eastern steppe zone from the distinctive isotopic signature it left behind in the bones of people who consumed it. In southern Siberia, this major transformation in diet is seen clearly from the late second millennium BC onwards, at a time when material connections with northwestern China and the Central Plains are also increasingly apparent (Svyatko et al., 2013). Wang et al. (2017) situate Tianshanbeilu at the centre of this process of agricultural exchange on the basis of 110 new stable isotopic data (carbon and nitrogen) of human bones from the site describing and "isotopic millet road" across Eurasia.

A critical obstacle that keeps us from further understanding how the networks centred on Tianshanbeilu were gradually established and expanded is the relatively low chronological resolution of the site. Unlike chronological studies in the Central China, which can rely not only upon pottery typology, stratigraphy and radiocarbon dating, but also on various textual evidence such as oracle bones or bronze inscriptions, very few techniques apart from typology and radiocarbon can be employed to date a steppe culture site in Xinjiang. It is even more challenging in the context of Tianshanbeilu since the stratigraphic sequence of the cemeteries is extremely difficult to establish. For a rather long period, the discussion of the absolute chronology of 
Tianshanbeilu has been based on only six radiocarbon dates published in the 1990s, amongst which one is probably beyond the time span of interest (ZK2790, 7176 \pm 110 BCE, IA CASS, 1996). Another four radiocarbon dates are published in Wang et al. (2017). Using Bayesian modelling in OxCal (Bronk Ramsey, 1998), the start and end boundary falls into 1943-1763 BCE and 1127-931 BC (95.4\% probability), respectively (Yang, 2018; Ma et al. submitted). Further analysis by kernel density estimation and summed function in OxCal agrees that the major body of Tianshanbeilu ranges from around $1800 \mathrm{BCE}$ to $1000 \mathrm{BCE}$ (Bronk Ramsey, 2018). This date range is consistent with the chronological range of potential material correlates identified for this material (Figures. 1a \&b), but does not, at present, allow us to explore more precisely the chronology of contact between China and the steppe in eastern Xinjiang.

\section{Materials, Methods and Results}

Forty-six metal objects were selected for analysis in this project, which is part of a larger conservation project on Xinjiang bronzes organized by Northwest University of China (Online supplementary material I). Due to heavy corrosion, only sixteen objects yielded reliable compositional results (see discussion below), while thirtyeight objects yielded lead isotope results (Figure 2; Tables 1 and 2).

\subsection{Alloying composition and impurity elements}

The compositional analysis was conducted in the Conservation Laboratory of Shaanxi Provincial Institute with scanning electron microscopy and energy dispersive spectrometry (SEM: ZEISS EVO MA25; EDS: XMax 20 of Oxford UK). All of the samples were measured under the parameters of $20 \mathrm{KeV}$, live time 120s (dead time around $30 \%$ ) and calibrated using the default standardless mode. The minimum detectable limit for the majority of elements is estimated to be $0.1 \%(\mathrm{Cu}, \mathrm{Sn}, \mathrm{Pb}, \mathrm{Sb}, \mathrm{Ag}, \mathrm{Ni}, \mathrm{Fe}, \mathrm{Co})$ but it increases to $0.15 \%$ for $\mathrm{As}$ and $\mathrm{Bi}$ and $0.2 \%$ for $\mathrm{Zn}$ due to the overlap in the energy spectrum. More details of the operational process can be found in (Liu, 2016).

A series of pilot analyses were conducted before the main analytical sequence in order to assess the degree of corrosion of the samples and its likely effects on the analysis. It is well known that the corrosion of metal is a complex process and that corrosion products often show significant enrichment/depletion of elements with respect to the original chemistry of the metal alloy. During this process, particular attention was paid to the total of each analysis, as this serves as the primary index of data quality. Generally speaking, totals from this SEMEDX analysis should fall within $98-102 \%$. A second indicator of data quality and no less important is the concentration of oxygen. A high percentage of oxygen within the analytical total strongly indicates the presence of corrosion products. After careful examination of the whole sample, five areas of each sample were selected for full measurement using the parameters listed above. However, even if after the first run of filtering a few measurements still show rather high percentage of oxygen ( $>\sim 10 \%$, see online supplementary material), which have to be abandoned. The rest measurements are subsequently averaged and normalize the average (Table 1; See online supplementary material II for all the individual analyese).

The major issue is that the copper objects from Xinjiang are invariably heavily corroded, and the most likely explanation for the high but variable oxygen is that the analysis is including a variable proportion of oxidized metal. Where the oxygen is high, therefore, the remainder of the analysis does not necessarily represent the core metal, but an unknown combination of core metal and oxidized corrosion product. It is tempting to simply remove the oxygen by normalizing the other components to $100 \%$, but this is unlikely to give a representative analysis, since the corrosion product may contain elements scavenged from the local environment, and the corrosion process can lead to the selective loss of certain elements, thus apparently enriching the others. This is also the case for the previously published data from this area. Mei (2001) published the analyses of 19 objects from Tianshanbeilu, with oxygen recorded as between 0 and 42.3\% (average c. 13.5\%). Qian (2006) published data from 89 objects: oxygen was not reported, but the analytical totals were systematically low, suggesting that between 0 and $6.64 \%$ could have been oxygen. The chemical analysis of such objects presents a significant challenge. In this paper, we have taken $10 \%$ oxygen to be the maximum acceptable value. Where the five spot analyses all record $<10 \%$ oxygen we have simply averaged all five. Where one or more of the five spot analyses record $>10 \%$ oxygen, we have averaged the remaining analyses (and recorded the number of analyses in the average. Where all five analyses have $>10 \%$ oxygen we have rejected the whole analysis.

\subsection{Lead isotopic analyses}

The lead isotopic measurements were carried out at the laboratory of Earth and Space Sciences at Peking University, using VG Elemental Multicollector-Inductively Coupled Plasma Mass Spectrometer (MC-ICP-MS). Each time it was calibrated by measuring the internationally agreed standards NBS 981 to minimize the standard 
deviation of the measurements (less than $0.02 \%$ ). About $50 \mathrm{mg}$ of each sample was dissolved in a nitric acid solution after washing and drying. Lead was then separated electrochemically by deposition onto a platinum electrode under weak nitric acid conditions. The lead on the platinum electrode was dissolved using a few drops of $2 \%$ nitric acid into a polyethylene bottle. The purified lead solution was measured by inductively coupled plasma atomic emission spectroscopy (ICP-AES) and then diluted by adding deionized water to 400-1000 ppb. The international standard T1 SRM997 was also added as internal calibration. All of the samples were subsequently moved to MC-ICP-MS for isotopic measurements and the final results are shown in Table 2.

\section{Discussion}

\subsection{Chemical Data}

The alloying technology in eastern Xinjiang has been extensively discussed in the existing literature (e.g. Mei, 2000; Qian, 2006). So far, a total of 107 analyses of metal have been published. Based on the commonly used cut-off of $1 \%$ for "deliberate alloying", the alloying technology at Tianshanbeilu involves pure copper, arsenical copper, arsenic bronze ( $\mathrm{Cu}-\mathrm{Sn}-\mathrm{As})$, tin-bronze, leaded bronze $(\mathrm{Cu}-\mathrm{Sn}-\mathrm{Pb})$, leaded copper and leaded arsenic bronze $(\mathrm{Cu}-\mathrm{Sn}-\mathrm{Pb}-\mathrm{As})$. This wide range of alloy types is quite typical of steppe metal assemblages (Pollard et al., 2017; Hsu, 2016; Chernykh, 1992). Patterns of mobility associated with pastoralism would likely result in varied or fluctuating supply of metal, leading to a more diverse spectrum of alloy compositions. Re-use and recycling old objects is an obvious strategy to maintain the amount of metal in circulation resulting in dispersed distributions of the alloying metals in the assemblage.

Relative to the huge number of leaded bronzes discovered in Central China, the particular feature of Steppe metallurgy is often considered to be the presence of arsenic in copper-based objects. In this project, many objects have been found to contain arsenic up to $2.71 \%$. One bead reported in Qian (2000) has the highest percentage of arsenic so far seen in Tianshanbeilu, at 9.58\%. For most objects arsenic is below 3\%. As shown in Figure 3, one distinctive feature of this assemblage is the co-occurrence of arsenic and antimony in the metal, a feature seen as particularly typical of metal production in the Bronze age of the northern Sayan (Bobrov et al., 1997). Plotting antimony against arsenic (both over 1\%: Figure 3b) reveals two clear correlations - one with essentially low but constant antimony, and one in which the arsenic and antimony are positively correlated. These two elements are often associated with one another in the form of minerals of the tennantite-tethrahedrite series, in which arsenic and antimony form a complete solid substitution series from the end members tennantite (Cu12As4S13) and tetrahedrite (Cu12Sb4S13). Therefore, the correlation presented in the data of Group I can be potentially explained by the use of tennantite-tethrahedrite or tennantite as part of the ore charge (Krismer et al., 2011). Being different from Group I, the four objects in Group II show distinctive concentrations of arsenic but not antimony. One likely explanation is the addition of arsenic ores during the process of smelting, which has been attested in a number of studies focused on the probably most well-known Bronze Age mining and smelting site, Nulasai (Figure 1, Mei, 2000; Li, 2001).

\subsection{Lead Isotopes}

Figure 4 shows a conventional pair of lead isotope diagrams for the data in Table 2. Clearly, the lead isotopic data are distributed into three groups. The majority of the data falls into a group with $17.7>\mathrm{Pb} 206 / \mathrm{Pb} 204>$ 18.6, which represents common lead (CL). A smaller group of three objects is also clearly distinguished at lower values of $\mathrm{Pb} 207 / \mathrm{Pb} 204$ and $\mathrm{Pb} 208 / \mathrm{Pb} 204$. The most interesting 'group', however, is the first, consisting of only one data point (sample M571:2), but showing highly radiogenic lead (HRL, for which our definition is $\mathrm{Pb} 206 / \mathrm{Pb} 204>19)$. This is so far the first object presenting a highly radiogenic signature found in Xinjiang. It was discovered in tomb M571, tentatively dated to Phase III of Tianshanbeilu (ca. 1500-1300 BC, (Yang, 2018; Ma et al. submitted), which corresponds to the Shang period (ca. 1500-1045 BC). It is too fragmented to be typologically diagnostic (Figure 2), but is described as a plaque, which means that it is a Steppe-type object rather than a fragment of imported central Chinese bronze ritual vessels.

Figure 5 shows the available lead isotope data for modern copper or lead ores in Xinjiang. There is a good overlap between the majority of the common Tianshanbeilu lead (Group II in Figure 4) and the ore data, suggesting that a local source of lead is possible. The smaller group in Figure 4 (Group III) is not as yet matched by any known Xinjiang source. Apart from one bornite (Cu5FeS4) sample from western Xinjiang containing highly radiogenic lead, so far there is little evidence to suggest a local mine which is capable of producing the 'Tianshanbeilu' type of HRL (Group I). Of course, this does not preclude such a source, since the bornite sample shows that HRL does exist in Xinjiang. More detailed archaeological and geological investigations into local ancient mines needs to be conducted around Xinjiang. 
Figure 6 compares the common lead isotopic data between Tianshanbeilu and the data from the Shang Sackler collection (Bagley, 1990), which reflects the lead in circulation in Central China. The slopes of the two isochrons are inconsistent, especially in $\mathrm{Pb} 208 / \mathrm{Pb} 204$ vs $\mathrm{Pb} 206 / \mathrm{Pb} 204$. This suggests that the ore bodies which these two groups of lead derive from may have different geological ages or have followed a different evolutionary line. This difference is sufficient to suggest that the metal in Tianshanbeilu does not represent recycled metal from Central China.

Previous work by many scholars has accumulated over one thousand measurements of lead isotopic data for bronzes distributed across Central China and the Yangtze River area (Liu et al., 2015; Liu et al., 2018; Jin, 2008; Jin, et al., 2017; Chen et al. 2019). The primary concern of most researchers has been centred on the provenance of this lead, but no consensus has yet been reached, and there is still uncertainty about whether this lead is the result of exploitation of a single source of lead, or many. However, these data show that approximately half of the bronzes recovered from Anyang contain HRL, and that bronzes containing HRL are widely spread over Central China. The work of Cao (2014) has significantly extended the distribution of HRL towards the north, where he has discovered a substantial number of such bronzes in the highlands of Shaanxi and Shanxi. Based on the chemical compositions and typological analysis, he argues that the reason for the appearance of Anyangcomposition leaded bronze in these regions is a result of exchanging Anyang bronzes for horses, with some objects being recycled into local forms (Cao, 2014).

A further issue to consider therefore is whether HRL was locally available in Tianshanbeilu. New analytical work has shown the appearance of HRL in the west, such as in the Hexi Corridor. At the Gansu Mogou site, a considerable number of objects have been discovered containing HRL (Wang, 2019). Likewise, copper ores and objects excavated from the Bronze Age sites in the Hexi Corridor show clear radiogenic signatures (Chen et al. accepted, Dodson et al., 2009). Figure 4a plots the data from the Hexi Corridor and Tianshanbeilu for comparison, and $4 \mathrm{~b}$ shows a comparison between the data from the Shang Sackler collection (representing the objects at Anyang) and all of the data from Tianshanbeilu, including the HRL sample. This is obviously inconsistent with the reported values from the Hexi corridor (Figure 7a), particularly in terms of Pb208/Pb204, suggesting a difference in the thorium environment between the ore sources of the two sets of samples. Figure $7 \mathrm{~b}$ shows that the Tianshanbeilu HRL sample is consistent with the isotopic pattern from the objects in the Shang Sackler Collection (representing the metal in circulation in Central China), suggesting that this sample may represent an object re-made from metal originating in the Shang centre. However, the low lead content of this object $(0.34 \%)$ indicates that is unlikely to simply be recycled Central Chinese metal, which tends to contain much more lead ( 2-30\%). In the light of this, we suggest that this sample represents the use of a source of lead containing HRL, from a source as yet unknown, but most likely in Xinjiang.

\section{Conclusions and further perspectives}

(1) The new analyses of copper-based objects at Tianshanbeilu have revealed a number of interesting points regarding the metallurgy during the second millennium BC around eastern Xinjiang. The new chemical data presented here illustrates a problem which can also be seen in other similar data sets - the metal objects tend to be small and thin, and are often corroded all through. This is most easily seen when the percentage oxygen is reported, since uncorroded copper contains dissolved oxygen at less than a fraction of a percent. Further work is required to understand how best to use such data, but the approach adopted here is to simply eliminate samples which contain more the $10 \%$ oxygen.

(2) The general paucity of metal objects suggests that the Tianshanbeilu people did not enjoy an abundant supply of metal. Even so, the metals they employed clearly derived from more than one source, as evidenced by the range of alloy types represented, and also the lead isotope data. Although tin-bronze is the most ubiquitous local alloying type, a variety of other combinations of metals have also been identified, including the use of ores from the tennantite-tetrahedrite series.

(3) The lead isotope data reveals the most significant finding of this paper - the occurrence of a single sample of heavily corroded $\mathrm{Cu}$-Sn-As alloy in the form of a plaque, containing highly radiogenic lead $\left(\mathrm{Pb}^{206} / \mathrm{Pb}^{204}=\right.$ 20.209). This is currently the furthest west that such lead has been found, and is currently the only example from Xinjiang. The widely discussed issue about the source of highly radiogenic lead in Shang dynasty bronzes is further complicated by the discovery of such lead in bronzes from Gansu and now from Xinjiang. This wide distribution must surely strengthen the view that there were multiple sources of HRL used in Bronze Age China. This does not of course imply that Anyang itself received such lead from more than one source - simply that more than one source supplied HRL to the many bronze-producing regions of China. 


\section{Acknowledgements}

This work is funded by ERC advanced project FLAME (Flow of Ancient Metal Across Eurasia, 670010), Social Science Research Fund of Shaanxi Province China (2014H02) and academic fund of Wolfson College (University of Oxford).

\section{References}

Bagley, R., 1990. Shang ritual bronzes: casting technique and vessel design. Archives of Asian Art, 43: 6-20.Bobrov, V.V., Kuzminykh, S.V., and Teneyshvili, T.O., 1997. Drevnyaya metallurgiya srednego Yeniseya (Lugavskaya Kul'tura). Kemerovo: Kuzbassvuzizdat, 1-12.

Bronk Ramsey, C., 1998. Probability and dating. Radiocarbon, 40: 461-474.

Bronk Ramsey, C., 2018. Methods for summarizing radiocarbon datasets. Radiocarbon, 59: 1809-1833.

Cao, D., 2014. The loess highland in a trading network (1300-1050BC). Unpublished PhD Thesis. Princeton University, 1380.

IA CASS (Institute of Archaeology, Chinese Academy of Social Science), 1996. Report of radiocarbon dating (23). Kaogu, 7: 66-70 (in Chinese).

Chen, G., 1990. Bronze Age and early Iron Age culture at Xinjiang. Kaogu, 4: 366-374 (in Chinese).

Chen, G., Cui, Y., Liu, R., Wang, H., Pollard, A. M., and Li, Y., accepted (online available). Lead isotopic analyses of copper ores in the early Bronze Age Central Hexi Corridor, northwest China. Archaeometry.

Chen, K., Mei, J., Rehren, T., Liu, S., Yang, W., Martinon-Torres, M., Zhao, C., Hirao, Y., Chen, J., and Liu, Y., 2019. Hanzhong bronzes and highly radiogenic lead in Shang period China. Journal of Archaeological Science, 101: 131-139.

Chernykh, E.N., 1992. Ancient metallurgy in the USSR: the early metal age. Cambridge: Cambridge University Press, 1-359.

Chernykh, E.N., 2017. Nomadic cultures in the megastructure of the Eurasian World (Trans. I. Savinetskaya and P. Hommel). Moscow: LRC press, 1-696.

Dodson, J., Li, X., Ji, M., Zhao, K., Zhou, X., and Levchenko, V., 2009. Early Bronze in two Holocene archaeological sites in Gansu, NW China. Quaternary Research, 72: 309-314.

Dong, G., Yang, Y., Han, J., Wang, H., Chen, F., 2017., Exploring the history of cultural exchange in prehistoric Eurasia from the perspectives of crop diffusion and consumption. Science China Earth Sciences, 60: 1110-1123.

Gong, G., 1997. Preliminary discussion of early coppers at Xinjiang. Kaogu, 9: 7-20 (in Chinese).

Han, J., 2007. Bronze Age and early Iron Age cultures at Xinjiang. Beijing: Wenwu press, 1-125 (in Chinese).

Han, R., and Sun, S., 2004. Preliminary studies on the bronzes excavated from the Tianshanbeilu cemetery, Hami, Xinjiang, in Linduff K (eds.). Metallurgy in ancient eastern Eurasia from the Urals to the Yellow river. Lampeter, Ceredigion, Wales: The Edwin Mellen Press, 157-172.

Hsu, Y.-K., 2016. The dynamic flow of copper and copper alloys across the prehistoric Eurasian steppe from 2000 to 300 BCE. Unpublished PhD thesis. University of Oxford, 1-130.

Jaang, L., 2015. The Landscape of China's Participation in the Bronze Age Eurasian Network. Journal of World Prehistory, 28: $179-213$.

Jin, Z., 2008. Lead isotopic archaeology in China. Beijing: Press of University of Science and Technology, 1-233 (in Chinese).

Jin, Z., Liu, R., Rawson, J., and Pollard, A.M., 2017. Revisiting lead isotope data in Shang and Western Zhou bronzes. Antiquity, 91: 1574-1587.

Krismer, M., Vavtar, F., Tropper, P., Kaindl, R., and Sartory, B., 2011. The chemical composition of tetrahedrite-tennantite ores from the prehistoric and historic Schwaz and Brixlegg mining areas (North Tyrol, Austria). European Journal of Mineralogy, 23: 925-936.

Kuzmina, E.E., 2007. The Origin of the Indo-Iranians and the Prehistory of the Silk Road. Leiden: Brill, 1-763.

$\mathrm{Li}$, S., 2002. The interaction between northeast China and Central Asia during the second millennium BC: an archaeological perspective., in Boyle K, Renfrew C, and Levine M. (eds.). Ancient interactions: east and west in Eurasia. Cambridge: McDonald Institute for Archaeological Research, 171-181.

Li, S., 2005. Trans-regional interaction of early metallurgy between northwest China and the Central Plains. Kaogu xuebao, 3: 239-278 (in Chinse with English abstract).

Li, S. 2009. Study of the archaeological Tianshanbeilu mudi yiqi yicun yanjiu, in Chinese Nationa Museum, and School of Archaeology and Museology Beijing University (eds.). Essay Collection of Yuweichao. Beijing: Wenwu press, 193-202 (in Chinse with English abstract).

Li, S., and Shui, T., 2000. The Study of the Siba Cultural copper objects. Wenwu, 3: 36-44 (in Chinse with English abstract).

Li, Y., 2001. Study on Smelting Technology of the Nulasai site in Nileke county, Xinjiang. Nonferrous Metals, 53: 64-66 (in Chinse with English abstract).

Linduff, K.M., 2004. Metallurgy in ancient eastern Eurasia from the Urals to the Yellow River. Lewiston, New York: Edwin Mellen Press, 1-315.

Liu, R., 2016. Capturing changes: applying the Oxford system to further understand the movement of metal in Shang China. Unpublished PhD thesis. University of Oxford, 1-278.

Liu, R., Bray, P., Pollard, A.M., and Hommel, P., 2015. Chemical analysis of ancient Chinese copper-based objects: Past, present and future. Archaeological Research in Asia,3: 1-8.

Liu, R., Rawson, J., and Pollard, A.M., 2018. Beyond ritual bronzes: identifying multiple sources of highly radiogenic lead across Chinese history. Scientific Reports, 8: 11770.

Liu, R., Pollard, A. M., Rawson, J., and Schulting, R., accepted. Dietary Changes Across Chinese History: Synthesis of Stable Isotopic Data for Human Bone Collagen. Holocene.

Mei, J., 2000. Copper and bronze metallurgy in late prehistoric Xinjiang: its cultural context and relationship with neighbouring regions. Oxford: Archaeopress, 1-93.

Ma, J., Tong, J., Liu, G., Li, W., Chang, X., Yu, J, Ma. Y., Tian, Y. Mu, L. Liu, R., submitted. Chronology of Tianshanbeilu cemetery and early development of Hami oasis during the 2nd millennium BC. Radiocarbon.

Mei, J., 2003. Cultural Interaction between China and Central Asia during the Bronze Age. Proceedings of the British Academy, 121: 1-39.

Mei, J., and Shell, C., 1999. The existence of Andronovo cultural influence in Xinjiang during the 2nd millennium BC. 
Antiquity, 73: 570-578.

Mei, J., Wang, P., Chen, K., Wang, L., Wang, Y., and Liu, Y., 2015. Archaeometallurgical studies in China: some recent developments and challenging issues. Journal of Archaeological Science, 56: 221-232.

Millard, J.A., 2007. Eurasian crossroads: a history of Xinjiang. New York City: Columbia University Press, 1-352.

Pollard, A.M., Bray, P., Hommel, P., Hsu, Y.-K., Liu, R., and Rawson, J., 2017. Bronze age metal circulation in China. Antiquity, 91: 674-687.

Qian, W., 2006. The Prehistoric Copper and Bronze of Hami Region in Xinjiang and Their Contexts of Neighboring Cultures. Beijing: Zhishi chanquan press, 1-168 (in Chinse with English abstract).

Rawson, J., 2010. Carnelian beads, animal figures and exotic vessels: traces of contact between Chinese states and Inner Asia, ca 1000-650 BC, in Wagner, M., and WANG, W (ed.), Bridging Eurasia. Mainz: Von Zabern, 5-12.

Sherratt, A., 2006. The trans-Eurasian exchange: The prehistory of Chinese relations with the West, in Mair V M (eds.). Contact and exchange in the ancient world. Honolulu: University of Hawaii Press, 32-53.

Shui, T., 1993. Comparison of archaeological cultures in Bronze Age Xinjiang. Guoxue yanjiu, 01: 1-13 (in Chinese).

Svyatko, S. V., Schulting, R. J., Mallory, J., Murphy, E. M., Reimer, P.J., Khartanovich, V. I., Chistov, Y. K., and Sablin, M. V., 2013. Stable isotope dietary analysis of prehistoric populations from the Minusinsk Basin, Southern Siberia, Russia: a new chronological framework for the introduction of millet to the eastern Eurasian steppe. Journal of Archaeological Science, 40: 3936-3945.

Vadetskaya, E. B., Polyakov, A. V., and Stepanova, N. F., 2014. Svod Pamyatniki Afanasievskoy Kul'tury. Barnaul: Azbuka, $1-45$.

Wang, T., Wei, D., Chang, X., Yu, Z., Zhang, X., Wang, C., Hu, Y., and Fuller, B. T., 2017. Tianshanbeilu and the Isotopic Millet Road: reviewing the late Neolithic/Bronze Age radiation of human millet consumption from north China to Europe. National Science Review, 00: 1-16.

Wang, Y., 2019. Scientific Study on Copper and Bronze Artefacts of the Lower Xiajiadian Culture. PhD thesis. University of Science and Technology Beijing, 1-72.

Yang, C. 2018. Scientific Study On The Bronzes From Tianshanbeilu Cemetery. Unpublished Master thesis. Northwest University China, 1-96.

Zhang, L., 2017. The Transmission of the Karasuk Metallurgy to the Northern Zone of China. Shidi, 1: 100-124.

\section{About the first author}

Liu Cheng, male, born in 1964 in Shanghai; Master; graduated from Northwest University China; associated professor of the School of Cultural Heritage, Northwest University China. He is now interested archaeological and conservation science. Email: liucheng@nwu.edu.cn; phone: +86 13772137915.

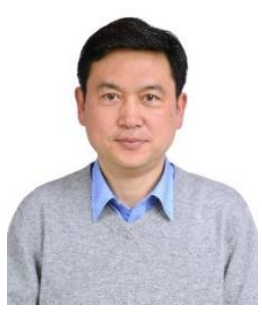

\section{About the corresponding author}

Liu Ruiliang, male, born in 1988 in Ji'nan City, Shandong Province; DPhil; graduated from the University of Oxford; Junior Research Fellow in Wolfson College and postdoctoral researcher in the School of Archaeology, University of Oxford. He is interested in archaeometallurgy, radiocarbon dating and east-east communication in antiquity. Email: ruiliang.liu@arch.ox.ac.uk, phone: +44 01865285219

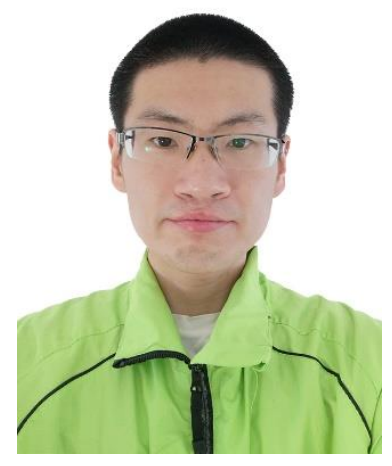


Figure $1 \mathrm{a} \& \mathrm{~b}$. General distribution of the main Bronze Age archaeological cultures/culture-historical communities of the steppe-desert zone showing possible typological relationships with the material from TSBL.

1a- c. 2000-1500 BC-i) sites and materials attributed to the Andronovo culture; ii) sites and materials attributed to the Okunev/Okunev type cultures; iii) Main sites discussed in this paper (distributions collated from Mei and Shell, 1999; Kuzmina, 2007; Vadetskaya, et al., 2014); 1b-c. 1500-1000 BC - i) sites and materials attributed to the Karasuk and Irmen cultures; ii) general distribution of deerstone monuments with depictions of Karasuk-style artefacts; iii) sites and materials attributed to the Cordoned Ware horizon (distributions collated from Agapov et al., 2014).

Figure 2 Some of the objects selected for chemical and isotopic analysis (a full list of sampled objects can be found in the online supplementary materials associated with this article).

Figure 3 Plotting arsenic and antimony of the Tianshanbeilu metals

Figure 4 Lead isotopic groupings at Tianshanbeilu

Figure 5 Comparison of lead isotopic data between the Tianshanbeilu objects and the modern ores of Xinjiang (sources of data are in the online supplementary materials)

Figure 6 Comparing common lead isotopic data between Tianshanbeilu and Central China

Figure 7 Comparison of lead isotopic data of Tianshanbeilu, the Hexi Corridor and the Shang Sackler Collection (Data from Chen et al., accepted; Dodson et al., 2009).

Table 1. Compositional results based on SEM-EDS

Table 2. Results of lead isotopic analysis 
